\title{
MASSIVE SPLEEN: A HIDDEN DANGER!
}

Shetty Tanvi, Ksheera Cariappa, Umaru N, Sushmita M. G.
1. Post Graduate. Department of Pathology A. J. Institute of Medical Sciences.
2. Post Graduate. Department of Pathology A. J. Institute of Medical Sciences.
3. Professor \& HOD. Department of Pathology A. J. Institute of Medical Sciences.
4. Post Graduate. Department of Pathology A. J. Institute of Medical Sciences.

\section{CORRESPONDING AUTHOR:}

Dr. Shetty Tanvi,

B-403,Casuarina,

Evershine Greens,New link Road,

Andheri West, Mumbai-400102

E-mail:tanvi420@gmail.com

AIMS: To determine the cause for massive splenomegaly. MATERIALS AND METHODS: Splenectomy was done and sections given from cut surface. They were stained with haemotoxylin \& eosin and microscopically analysed. Immunohistochemical study was done for a panel of antibodies including CD5, CD10, CD20, bcl-2 \& cyclin D1. RESULTS: Microscopy showed effacement of the normal architecture along with a nodular architecture in the white pulp with small lymphocytes surrounded by medium to large lymphoid cells with dispersed chromatin and abundant pale cytoplasm which resembled the marginal zone cells. Immunohistochemical study showed positivity for CD20 and bcl -2. It was negative for CD5, CD10 and Cyclin D1. Considering all the findings a diagnosis of Splenic Marginal Zone Lymphoma (SMZL) was made.

CONCLUSION: In this case, clinically lymphoma was not suspected, as splenomegaly was the only finding. Patient was thoroughly investigated for various causes of splenomegaly but only histopathological evaluation of spleen along with IHC study was diagnostic.

INTRODUCTION: Splenic Marginal Zone Lymphoma (SMZL) is the term coined by Schmid et al. ${ }^{1}$ It accounts for $<1 \%$ of all lymphomas. ${ }^{2}$ It is indolent B cell malignancy usually involving spleen, bone marrow and blood. It is made up of B cells that replace normal architecture of white pulp of spleen. ${ }^{3}$ Symptomatic splenomegaly is the presenting feature in almost all patients; anemia related symptoms and B symptoms are rare. Spleen histology is the gold standard approach to establish a clear cut diagnosis of SMZL. ${ }^{4}$

CASE HISTORY: 65yr old male presenting only with splenomegaly and few atypical lymphoid cells in peripheral smear. Splenectomy was done.

MATERIALS \& METHODS: Sections were given from cut surface which were stained with haemotoxylin and eosin stains. Immunohistochemical study was done for a panel of antibodies including CD5, CD10, CD20, bcl-2 and cyclin D1.

RESULTS: Peripheral smear showed few atypical lymphoid cells. Splenectomy was done. The spleen was enlarged measuring $30 * 15 * 12 \mathrm{cms}$, weighing 1450 gms. Cut surface showed multiple nodules measuring $2 \mathrm{~mm}-4 \mathrm{~mm}$. Sections were given from cut surface and were stained with haemotoxylin and eosin. Microscopy showed effacement of the normal architecture, however there was a nodular architecture in the white pulp with small lymphocytes surrounded by 
medium to large lymphoid cells with dispersed chromatin and abundant pale cytoplasm which resembled the marginal zone cells. Immunohistochemical study showed positivity for CD20 and bcl -2. It was negative for CD5, CD10 and Cyclin D1.

DISCUSSION: In SMZL, the cell of origin is postulated to be a post germinal centre B cell with an unknown degree of differentiation. With splenic involvement requirement for diagnosis of SMZL; splenomegaly is seen in almost all patients, commonly without lymphadenopathy. Aside from the involvement of spleen, the bone marrow is frequently positive in patients with SMZL. Nodal and extranodal involvement is rare. ${ }^{3}$ The deletion of 7q 21-32 is seen in 40\% of SMZL patients. ${ }^{5}$ Most patients are older than 50 years. On gross, spleen shows micronodular appearance. Splenectomy specimen reveals bizonal/biphasic phenomenon/margination in the white pulp with small round lymphocytes in the center replacing the germinal center. Small round lymphocytes are in turn, surrounded by medium sized lymphocytes with more dispersed chromatin and abundant pale cytoplasm resembling marginal zone cells. Scattered transformed large lymphoid cells are also seen in the outer zone. Mantle zone is effaced. In red pulp-besides sinusoidal infiltration, small nodules are sometimes present with composition of tumor cells similar to that in periphery of white pulp follicles. Immunohistochemistry, SMZL is positive for CD19, CD20, CD22,bcl-2 and negative for CD5, CD10,CD23 and Cyclin D1.1

In this case the histopathology finding along with age of patient and presenting complaint coincides with that which has been described for SMZL. The differential diagnosis based on histopathology includes follicular lymphoma, mantle cell lymphoma, B-CLL. Hence, Immunohistochemistry was done to differentiate it. IHC was positive for CD20, bcl-2 and negative for CD5, CD10 and Cyclin D1 diagnostic of SMZL.

In this particular case, clinically lymphoma was not suspected, as splenomegaly was the only finding. Patient was thoroughly investigated for various causes of splenomegaly. Only histopathological evaluation of spleen along with IHC study was diagnostic.

\section{REFERENCES:}

1. Flow Cytometry and Immunohistochemistry for Hematological Neoplasms by Tsieh Sun. Case 23, Splenic Marginal Zone Lymphoma 205-208.

2. 2.Armitage JO, Weisenburger DD. "New approach to classifying non-Hodgkin's lymphomas: clinical features of the major histologic subtypes. Non-Hodgkin's Lymphoma Classification Project". J. Clin. Oncol.1998;16(8): 2780-95.

3. 3.Elaine Sarkin Jaffe, Nancy Lee Harris, World Health Organization, International Agency for Research on Cancer, Harald Stein, J.W. Vardiman. Pathology and genetics of tumours of haematopoietic and lymphoid tissues. World Health Organization Classification of Tumors.2003 Press

4. 4.Luca Arcaini, Marco Paulli. Splenic marginal zone lymphoma: hydra with many heads?Haematologica, 2009;95,Issue 4,534-537.

5. 5.Corcoran MM, Mould SJ, Orchard JA, et al. "Dysregulation of cyclin dependent kinase 6 expression in splenic marginal zone lymphoma through chromosome 7q translocations". Oncogene 1998;18 (46): 6271-7. 


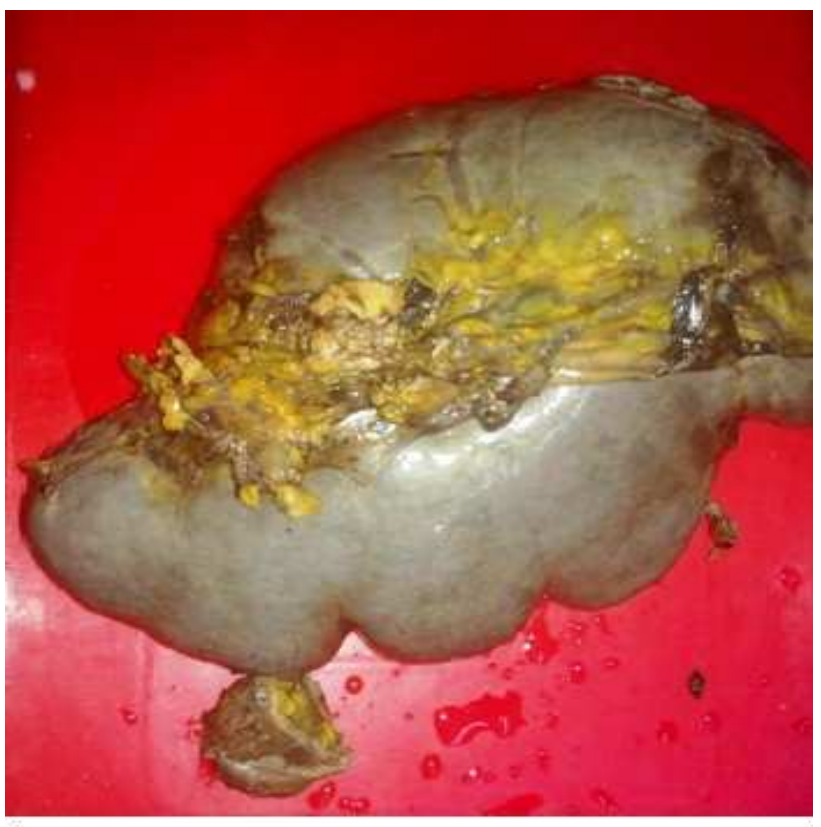

Fig 1. The spleen was enlarged measuring $30 * 15 * 12 \mathrm{cms}$.
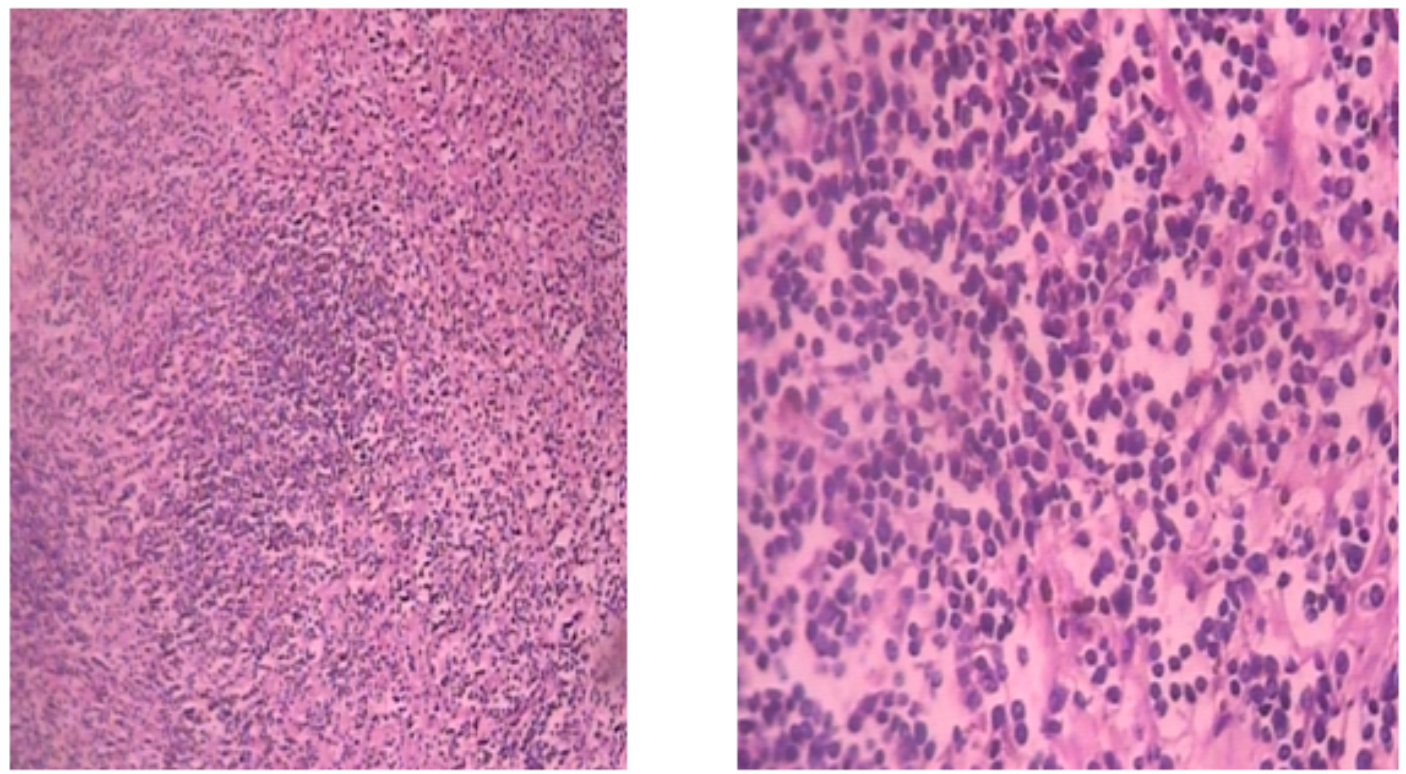

Fig 2(10X) \& 4(40X) shows nodular architecture in the white pulp with small lymphocytes surrounded by medium to large lymphoid cells with dispersed chromatin and abundant pale cytoplasm which resemble the marginal zone cells 


\section{CASE REPORT}

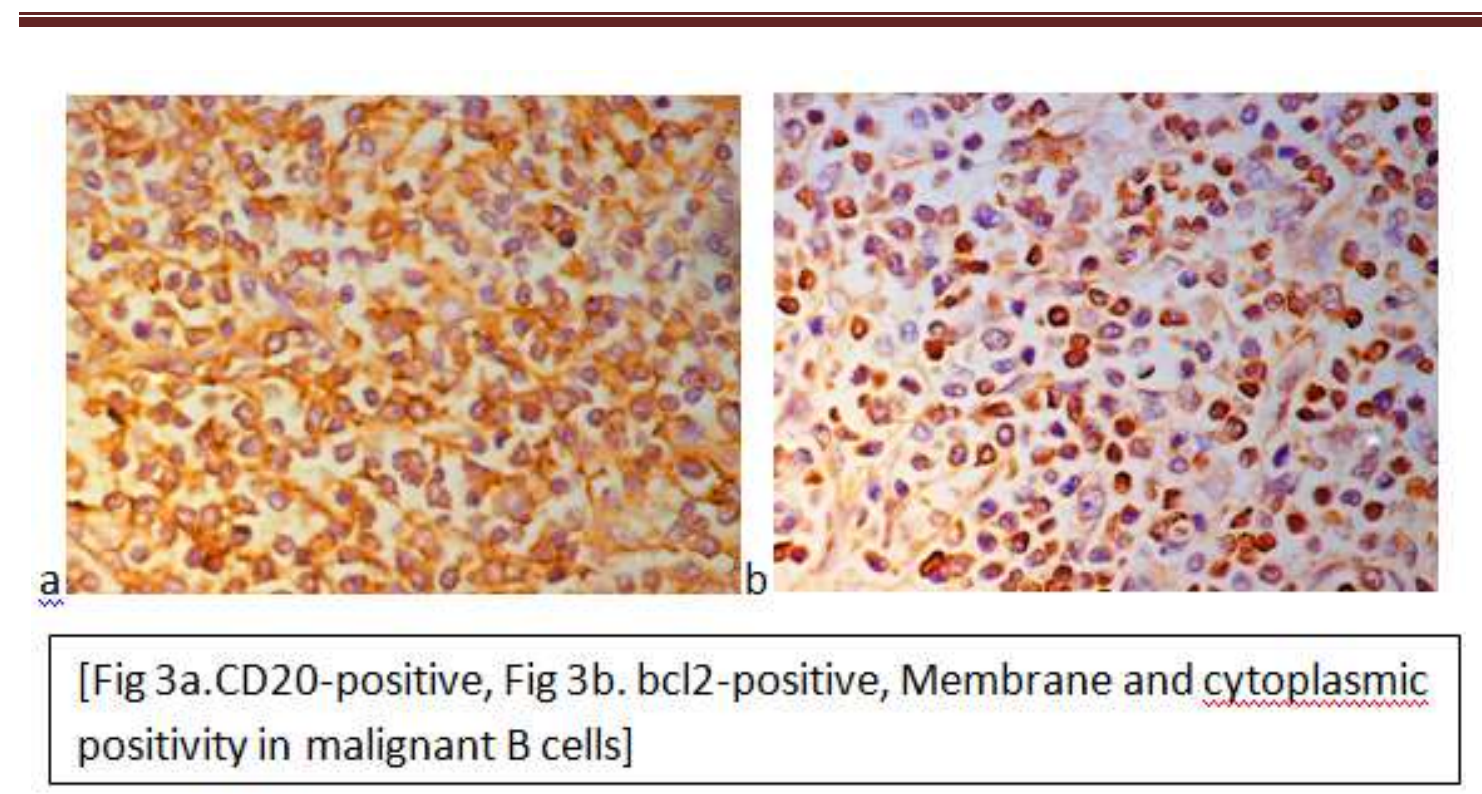

